\title{
Quantifying Unmet Need in Statin-Treated Hyperlipidemia Patients and the Potential Benefit of Further LDL-C Reduction Through an EHR-Based Retrospective Cohort Study
}

\author{
Titus Schleyer, DMD, PhD; Siu Hui, PhD; Jane Wang, PhD; Zuoyi Zhang, PhD; Kristina Knapp, BA; \\ Jarod Baker, MS; Monica Chase, PhD; Robert Boggs, PhD; and Ross J. Simpson, Jr, MD, PhD
}

\begin{abstract}
BACKGROUND: Statins are effective in helping prevent cardiovascular disease (CVD). However, studies suggest that only $20 \%-64 \%$ of patients taking statins achieve reasonable low-density lipoprotein cholesterol (LDL-C) thresholds. On-treatment levels of LDL-C remain a key predictor of residual CVD event risk.
\end{abstract}

OBJECTIVES: To (a) determine how many patients on statins achieved the therapeutic threshold of LDL-C $<100 \mathrm{mg}$ per $\mathrm{dL}$ (general cohort) and $<70 \mathrm{mg}$ per $\mathrm{dL}$ (secondary prevention cohort, or subcohort, with preexisting CVD); (b) estimate the number of potentially avoidable CVD events if the threshold were reached; and (c) forecast potential cost savings.

METHODS: A retrospective, longitudinal cohort study using electronic health record data from the Indiana Network for Patient Care (INPC) was conducted. The INPC provides comprehensive information about patients in Indiana across health care organizations and care settings. Patients were aged $>45$ years and seen between January 1, 2012, and October 31, 2016 (ensuring study of contemporary practice), were statin-naive for 12 months before the index date of initiating statin therapy, and had an LDL-C value recorded 6-18 months after the index date. Subsequent to descriptive cohort analysis, the theoretical CVD risk reduction achievable by reaching the threshold was calculated using Framingham Risk Score and Cholesterol Treatment Trialists' Collaboration formulas. Estimated potential cost savings used published first-year costs of CVD events, adjusted for inflation and discounted to the present day.

RESULTS: Of the 89,267 patients initiating statins, $30,083(33.7 \%)$ did not achieve the LDL-C threshold (subcohort: $58.1 \%$ ). In both groups, not achieving the threshold was associated with patients who were female, black, and those who had reduced medication adherence. Higher levels of preventive aspirin use and antihypertensive treatment were associated with threshold achievement. In both cohorts, approximately $64 \%$ of patients above the threshold were within $30 \mathrm{mg}$ per $\mathrm{dL}$ of the respective threshold. Adherence to statin therapy regimen, judged by a medication possession ratio of $\geq 80 \%$, was $57.4 \%$ in the general cohort and $56.7 \%$ in the subcohort. Of the patients who adhered to therapy, $23.7 \%$ of the general cohort and $50.5 \%$ of the subcohort had LDL-C levels that did not meet the threshold. 10-year CVD event risk in the at-or-above threshold group was $22.78 \%$ ( $S D=17.24 \%$ ) in the general cohort and $29.56 \%(S D=18.19 \%)$ in the subcohort. By reducing LDL-C to the threshold, a potential relative risk reduction of $14.8 \%$ in the general cohort could avoid $1,173 \mathrm{CVD}$ events over 10 years (subcohort: $15.7 \%$ and 454 events). Given first-year inpatient and follow-up costs of $\$ 37,300$ per CVD event, this risk reduction could save about $\$ 1,455$ per patient treated to reach the threshold (subcohort: $\$ 1,902 ; 2017$ U.S. dollars) over a 10-year period.

CONCLUSIONS: Across multiple health care systems in Indiana, between $34 \%$ (general cohort) and $58 \%$ (secondary prevention cohort) of patients treated with statins did not achieve therapeutic LDL-C thresholds. Based on current CVD event risk and cost projections, such patients seem to be at increased risk and may represent an important and potentially preventable burden on health care costs.

J Manag Care Spec Pharm. 2019;25(5):544-54

Copyright $\odot 2019$, Academy of Managed Care Pharmacy. All rights reserved.

\section{What is already known about this subject}

Despite the effectiveness of statins in helping prevent cardiovascular disease (CVD), studies suggest that only 20\%-64\% of patients taking a statin achieve reasonable low-density lipoprotein cholesterol (LDL-C) thresholds.

Since on-treatment levels of LDL-C remain significant predictors of residual CVD event risk, the proportion of patients not achieving threshold LDL-C levels indicate an unmet preventive need of potentially important size.

\section{What this study adds}

In an Indiana population of 89,267 patients initiating statins, $33.7 \%$ of the cohort at large did not achieve therapeutic thresholds of LDL-C $<100 \mathrm{mg}$ per $\mathrm{dL}$, and $58.1 \%$ of a secondary prevention subcohort $(\mathrm{n}=15,313)$ did not achieve LDL-C $<70 \mathrm{mg}$ per $\mathrm{dL}$. Of patients who adhered to the statin therapy regimen, $23.7 \%$ of the general cohort and $50.5 \%$ of the subcohort had LDL-C levels that did not meet the threshold.

Achieving therapeutic thresholds would have reduced relative risk by $14.8 \%$ and avoided $\$ 1,455$ per patient in CVD event treatment costs for the general cohort (15.7\% and $\$ 1,902$, respectively, for the secondary prevention cohort) over a 10 -year period.

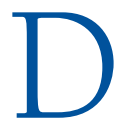
espite statins' clinical and cost-effectiveness in preventing and treating cardiovascular disease (CVD), substantial treatment gaps remain..$^{1-4}$ Twenty-nine percent of patients with heart disease are not being treated with statins, with health insurance and educational issues playing a role. ${ }^{5,6}$ However, even among patients treated with statins, only 20\%-64\% achieve their threshold low-density lipoprotein cholesterol (LDL-C) levels. ${ }^{7-14}$ An international comparison of 26 countries/regions puts this range even lower, from $14.3 \%$ in Germany to $49.5 \%$ in the United Arab Emirates and Kuwait, 
with an average of $28.1 \% \cdot{ }^{15}$ While the 2013 guidelines from the American College of Cardiology/American Heart Association (ACC/AHA) do not recommend thresholds, their 2018 update does, ${ }^{16,17}$ given successful outcomes studies of add-on therapies for high-risk patients. ${ }^{7}$ Importantly, on-treatment levels of LDL-C remain significant predictors of residual CVD event risk. ${ }^{18,19}$

The proportions of patients not achieving threshold LDL-C levels indicate an unmet preventive need. The size of these patient populations, the unmet need for prevention and treatment, and the resulting health care burden are of keen interest to health care organizations, clinicians, payers, and public health agencies. With statin therapy increasingly guided by cardiovascular risk assessment rather than specific thresholds of "normal" cholesterol, the scale and scope of statin treatment is expanding. ${ }^{16,20}$ At the same time, studies suggest that the lower the achieved cholesterol, the greater the cardiovascular benefit, at least for certain groups of patients with a history of CVD. ${ }^{21,22}$ Consequently, the unmet need for prevention and treatment is likely to grow. Therefore, it is important to assess the potential risk reduction in patients with dyslipidemia who have not achieved threshold LDL-C levels.

Quantifying this potential risk reduction is difficult using clinical trial or claims data alone. Electronic health record (EHR) databases, on the other hand, contain extensive clinical information, including measures of dyslipidemia, pharmaceutical interventions, and treatment outcomes. The Indiana Network for Patient Care (INPC), a health information exchange (HIE), provides one of the largest and most comprehensive sources of such information obtained from routine clinical care across multiple health care systems. ${ }^{23,24}$ The INPC aggregates information about patients being treated in over 90 hospitals and other health care facilities, most of whom are part of 5 major health systems (Indiana University Health, Eskenazi Health, Community Health Network, Franciscan Alliance, and St. Vincent). The INPC covers $66.7 \%$ of Indiana's population, and its data mirror the "integrated patient record" available to clinicians in integrated delivery networks. Fairly complete medical records available to clinicians in real time can often help determine a course of therapy better than partial, fragmented records. ${ }^{25}$ In addition, they tend to attenuate the common problem of data fragmentation plaguing retrospective database studies. ${ }^{26,27}$

As our health care system moves to value-based care, we must consider the financial implications of unrealized reductions in CVD risk. ${ }^{28}$ Costs of CVD events in the United States are substantial. ${ }^{29-31}$ For instance, in the analysis by Chapman et al. (2011) of insurance claims of 29,688 patients with a CVD event, mean initial inpatient costs were $\$ 16,981$ per case. ${ }^{30}$ Costs for CVD patients were higher than for matched controls without CVD: $\$ 13,792$ higher at 1-year follow-up, $\$ 20,862$ higher at 2 years, and $\$ 26,014$ higher at 3 years. For 16,615 nonelderly, commercially insured patients with hyperlipidemia and CVD events, health care costs averaged $\$ 50,809$ in the first year following an event. ${ }^{31}$ While numerous cost-effectiveness analyses for statins exist, ${ }^{4,32-34}$ only a subset analyze economic implications of lowering known risk factors for CVD. ${ }^{35-38}$

Our primary objective was to determine how many patients on statins failed to reach the therapeutic threshold of LDL-C $<100 \mathrm{mg}$ per $\mathrm{dL}$ (general cohort) and $<70 \mathrm{mg}$ per $\mathrm{dL}$ (secondary prevention cohort). We chose these thresholds because (a) our study period includes years when the Adult Treatment Panel III guidelines were still in effect, ${ }^{39}$ and (b) since the 2013 ACC/AHA guidelines were published, multiple outcomes trials of high-risk patients on statin therapy with LDL-C levels that remained elevated have shown the benefits of lowering LDL-C levels to reduce CVD risk. ${ }^{16,40-42}$ Anticipating these findings, the 2016 ACC consensus statement on the role of adjunctive nonstatin therapies to lower LDL-C supports the thresholds used in our study. ${ }^{7}$ After our study was concluded, the AHA reinstated thresholds for high-risk patients in their guidelines based on this evidence.

Secondary objectives included describing demographic and clinical characteristics, as well as concomitant health conditions; estimating the number of potentially avoidable CVD events if thresholds were reached and forecasting potential cost savings; and calculating the proportion of patients who were adherent but did not reach the LDL-C threshold.

This study makes 3 important contributions to the literature. First, because our dataset was drawn from an HIE, the data about each patient are likely more complete than those drawn from health care organizations or insurance claims databases. Second, our study population covered a health care market as opposed to a single health care system or integrated delivery network. Finally, we calculated CVD risk reduction that could occur if patients with LDL-C levels above the thresholds were able to lower their LDL-C below these thresholds and, subsequently, quantified economic implications.

\section{Methods}

Our retrospective, longitudinal cohort study used the medical records in the INPC. While many health care institutions contribute data to the INPC, we selected institution-specific datasets with the most complete and comprehensive data for this study.

The target cohort was patients initiating statin therapy in the INPC between January 1, 2012, and June 30, 2016, to ensure that patients received contemporary statin therapy modalities. The timeline shown in Figure 1 illustrates the following requirements for patient selection:

1. Patients are at least aged 45 years at the index date, which is the date of their first filled statin prescription.

2. Patients must be "patients of record" before the index date (at least 1 clinical encounter between 12 and 24 months before the index date). 
Index date (time $=0$ ):

- Patient aged $\geq 45$ years

- Statin prescription

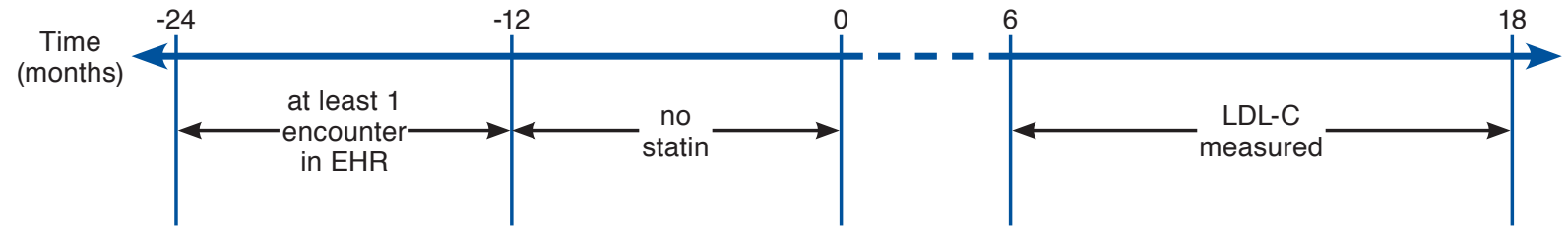

Note: The data timeline consisted of 4 key events: (1) beginning of study period (first possible date for observation) —January 1, 2011, which was predetermined per protocol based on need for recent data on statin treatment; (2) first possible index date-January 1, 2012, where patient had encounter on January 1, 2011, documented in the EHR and had not been prescribed statins since then (12-month statin-free period); (3) last possible index date-June 30, 2016, where patient was prescribed statin on June 30, 2016, and had LDL-C measured on December 31, 2016 (6 months after statin prescription); and (4) end of study period (last possible observation date) December 31, 2016, which was predetermined by project timeline.

$E H R=$ electronic health record; $L D L-C=$ low-density lipoprotein cholesterol.

3. The index date must be preceded by at least 12 months without a filled statin prescription. Patients are then considered statin-naive at the index date.

4. All patients initiating statin therapy in the study cohort were considered to have dyslipidemia at baseline. The rationale was that (a) statins are used for the prevention and treatment of CVD, and (b) we consider the judgment of the treating clinician as valid.

5. Only those patients with a recorded LDL-C measurement within 6-18 months after the index date and clinical notes (for extraction of important unstructured covariates) were included. We chose this time range, since the timing and frequency of laboratory tests for monitoring chronic conditions tend to vary.

The primary exposure in our study was statin therapy, and the index date was defined as the beginning of the exposure. We used the current list of statin medications from the MediSpan Electronic Drug File (see http://www.wolterskluwercdi. com/drug-data/medi-span-electronic-drug-file/) to identify statin prescriptions. We reported statins by intensity level, not specific drugs. Adherence to statin therapy, derived from pharmacy claims data and measured by the medication possession ratio, was defined as the number of days supplied for all statins filled as a percentage of the days from index date to outcome date (first qualifying lipid measurement).

The primary endpoint of our study was the first LDL-C measurement within 6-18 months from the index date. The endpoint was not intended to require continuous use of a statin. Our goal was to address the question, "If a physician prescribes a statin, what is the probability that 6 months later, the patient is at an acceptable LDL-C threshold?" Similar to a study by Jones et al. (2012), ${ }^{10}$ we conducted analyses for the cohort at large and a subgroup who received statins for secondary prevention. ${ }^{18,22,39,43,44}$ We defined secondary prevention patients as individuals who had a cardiovascular event before statin initiation or diabetes with evidence of coronary heart disease. The inclusion criteria for this subgroup mimicked those of the Merck REVEAL trial (2017). ${ }^{45}$

Dyslipidemia post-index date in the cohort at large was defined as an LDL-C level of greater than or equal to $100 \mathrm{mg}$ per $\mathrm{dL}$ at the first reading $(70 \mathrm{mg}$ per $\mathrm{dL}$ for the secondary prevention subcohort). Conversely, any patient whose LDL-C level was $<100$ (or $<70$ ) mg per dL was considered to have achieved the threshold. Descriptive analyses presented the 2 cohorts in terms of age, gender, ethnicity, triglycerides, systolic blood pressure, smoking, aspirin use for prevention of CVD, antihypertensive treatment, and comorbidities such as diabetes, congestive heart failure, peripheral artery disease, stroke, and prior myocardial infarction (MI). Comorbidities and other clinical characteristics were extracted from the coded diagnoses and structured data of EHRs before the index date, the only exception being smoking status, which was extracted by text mining of clinical notes that had a positive mention of smoking. For each cohort, the demographic and clinical characteristics were presented separately for the subgroups that did and did not reach LDL-C threshold, and simple 2-group comparisons were made using t-tests and chi-square tests. Variables with significant differences were entered into a multivariable logistic model to see if the differences remained significant after accounting for other characteristics.

Given the fact that several major risk scoring algorithms for CVD perform similiarly, we calculated the residual risk for CVD events using the Framingham Risk Score for 10-year CVD risk (FRSCVD; available at: https://www.framinghamheartstudy. org/fhs-risk-functions/cardiovascular-disease-10-year-risk/). ${ }^{46}$ For patients whose LDL-C levels did not reach the threshold, 


\begin{tabular}{|c|c|c|c|}
\hline TABLE & \multicolumn{3}{|c|}{$\begin{array}{l}\text { General Description of Patient Cohort } \\
\text { Treated with Statins, Grouped by } \\
\text { Whether LDL-C Threshold }<100 \text { mg } \\
\text { per dL Was Met or Not }\end{array}$} \\
\hline Demographics & $\begin{array}{c}\text { Patients with } \\
\text { LDL-C }<100 \mathrm{mg} \\
\text { per dL } \\
\text { n (\%) }\end{array}$ & $\begin{array}{l}\text { Patients with } \\
\text { LDL-C } \geq 100 \mathrm{mg} \\
\text { per dL } \\
\mathrm{n}(\%)\end{array}$ & $P$ Value ${ }^{a}$ \\
\hline Total & $59,184(66.3)$ & $30,083(33.7)$ & - \\
\hline \multicolumn{4}{|l|}{ Age } \\
\hline Mean, (SD) & $68(10.8)$ & $64(10.7)$ & $<0.001$ \\
\hline $45-54$ & $7,667(13.0)$ & $6,819(22.7)$ & \multirow{4}{*}{$<0.001$} \\
\hline $55-64$ & $14,037(23.7)$ & $8,735(29.0)$ & \\
\hline $65-74$ & $21,317(36.0)$ & $9,445 \quad(31.4)$ & \\
\hline$\geq 75$ & $16,163 \quad(27.3)$ & $5,084(16.9)$ & \\
\hline \multicolumn{4}{|l|}{ Gender } \\
\hline Female & $29,036(49.1)$ & $18,891(62.8)$ & \multirow{2}{*}{$<0.001$} \\
\hline Male & $30,148(50.9)$ & $11,192 \quad(37.2)$ & \\
\hline \multicolumn{4}{|l|}{ Ethnicity } \\
\hline Black & $3,299 \quad(5.6)$ & $2,601 \quad(8.7)$ & \multirow{3}{*}{$<0.001$} \\
\hline Other & $2,935 \quad(5.0)$ & $1,554 \quad(5.2)$ & \\
\hline White & $52,607 \quad(89.4)$ & $25,655(86.1)$ & \\
\hline Missing & 343 & 273 & - \\
\hline \multicolumn{4}{|c|}{ Clinical and laboratory characteristics } \\
\hline \multicolumn{4}{|l|}{ Triglyceride } \\
\hline Mean (SD) & $146(26.2)$ & $208(34.2)$ & \multirow{2}{*}{$<0.001$} \\
\hline Missing & 2,385 & 1,816 & \\
\hline \multicolumn{4}{|c|}{ Systolic blood pressure } \\
\hline Mean (SD) & $129(17.8)$ & $131(18.6)$ & $<0.001$ \\
\hline Missing & 48,590 & 24,727 & - \\
\hline \multicolumn{4}{|l|}{ Smokingb } \\
\hline & $12,316(32.1)$ & $6,101 \quad(33.7)$ & $<0.001$ \\
\hline Missing & 20,793 & 11,993 & - \\
\hline \multicolumn{4}{|l|}{ Aspirin } \\
\hline Before $^{c}$ & $19,002(32.1)$ & $7,257(24.1)$ & $<0.001$ \\
\hline Afterc & $27,092(45.8)$ & $11,267 \quad(37.5)$ & $<0.001$ \\
\hline \multicolumn{4}{|c|}{ Antihypertensive treatment } \\
\hline Before $^{c}$ & $29,389(49.7)$ & $12,684(42.2)$ & $<0.001$ \\
\hline Afterc & $39,249(66.3)$ & $16,705(55.5)$ & $<0.001$ \\
\hline \multicolumn{4}{|c|}{ Compliance with statin regimen (MPR $\geq 80 \%$ ) } \\
\hline & $39,113(66.1)$ & $12,125(40.3)$ & $<0.001$ \\
\hline Missing & $\begin{array}{c}14 \\
\text { (before index date) }\end{array}$ & $\begin{array}{c}5 \\
\text { (after index date) }\end{array}$ & - \\
\hline \multicolumn{4}{|c|}{ Intensity of initial statin regimen } \\
\hline High & $11,767 \quad(19.9)$ & $4,003(13.3)$ & \multirow{3}{*}{$<0.001$} \\
\hline Moderate & $42,636(72.0)$ & $22,669(75.4)$ & \\
\hline Low & $4,781 \quad(8.1)$ & $3,411 \quad(11.3)$ & \\
\hline \multicolumn{4}{|c|}{ Health conditions } \\
\hline Diabetes-afterc & $20,278(34.3)$ & $7,051 \quad(23.4)$ & $<0.001$ \\
\hline $\begin{array}{l}\text { Congestive } \\
\text { heart failure }\end{array}$ & $6,726 \quad(11.4)$ & $1,873 \quad(6.2)$ & $<0.001$ \\
\hline$\overline{P A D}$ & $4,051 \quad(6.8)$ & $1,330 \quad(4.4)$ & $<0.001$ \\
\hline Stroke & $4,392 \quad(7.4)$ & $1,577 \quad(5.2)$ & $<0.001$ \\
\hline Prior MI & $6,102 \quad(10.3)$ & $1,806 \quad(6.0)$ & $<0.001$ \\
\hline \multicolumn{4}{|c|}{$\begin{array}{l}\text { Note: All values in this table are } n \text { (\%) unless indicated otherwise. } \\
\text { aP values denote the statistical significance of differences for values within rows. } \\
\text { bSmoking was mentioned in clinical notes before and up to the index date. } \\
\text { 'Missing days-of-supply data. } \\
\text { LDL-C=low-density lipoprotein cholesterol; MI = myocardial infarction; } \\
\text { MPR = medication possession ratio; } P A D=\text { peripheral artery disease; SD=standard } \\
\text { deviation. }\end{array}$} \\
\hline
\end{tabular}

the theoretical reduction in relative risk of CVD achievable by reducing the observed LDL-C to the threshold was calculated using Cholesterol Treatment Trialists' (CTT) Collaboration estimates (available at: https://www.ctsu.ox.ac.uk/research/ctt). The CTT found that each $1.0 \mathrm{mmol}$ per L (38.67 $\mathrm{mg}$ per $\mathrm{dL}$ ) decrease in LDL-C reduced the annual rate of major vascular events, such as heart attack, revascularization, and ischemic stroke, by just over 20\%. Assuming the LDL-C of all patients in the overall cohort who did not reach the threshold could be reduced to $<100 \mathrm{mg}$ per $\mathrm{dL}$, the theoretical reduction in LDL-C ([LDL-C -100$] \div 38.67 \mathrm{mmol}$ per L) translates to a relative risk reduction in 1-year CVD risk ([LDL-C-100] $\div 38.67 \times 20 \%$ ). Applying the relative risk reduction to an individual with a given FRSCVD at a given LDL-C $\geq 100 \mathrm{mg}$ per $\mathrm{dL}$, the absolute 10-year risk of CVD can theoretically be reduced by an amount equal to FRSCVD $\times([$ LDL-C -100$] \div 38.67 \times 20 \%)$ if the treatment threshold were reached. Similarly, the potential absolute CVD risk reduction for individuals not reaching the LDL-C threshold of $<70 \mathrm{mg}$ per $\mathrm{dL}$ in the secondary prevention cohort is theoretically equal to FRSCVD $\times([$ LDL-C -70$] \div$ $38.67 \times 20 \%$ ).

We calculated potential cost savings as a function of the potential risk reduction based on published costs of CVD outcomes. ${ }^{30,31}$ According to Chapman et al., the 12-month costs for a CVD event were $\$ 30,773$ ( $\$ 16,981$ inpatient costs $+\$ 13,792$ first-year follow-up costs) in 2006, or $\$ 43,437$ in 2017 U.S. dollars $\left(\$ 30,773 \times 1.4115 ;\right.$ https://www.bls.gov/cpi/home.htm). ${ }^{30}$ Over a 10-year period, a CVD is assumed, on average, to occur in Year 5. Thus, today's CVD cost of $\$ 43,437$ must be discounted by $3 \%$ per year, yielding an average event cost of $\$ 43$, $437 \times(1-0.03) \wedge 5=\$ 37,300$ over 10 years. The theoretical total cost savings because of hypothetical achievement of threshold LDL-C by each at-or-above-threshold patient then equals $\$ 37,300 \times$ (potential reduction in CVD risk).

This project was classified as "expedited" by the Indiana University Institutional Review Board (protocol number 1612472480). All study data were deidentified per the Health Insurance Portability and Accountability Act (HIPAA) of 1996 Safe Harbor Protocol.

\section{Results}

\section{Descriptive Analyses for the Cohort at Large}

Beginning with a total of 659,687 patients who had a record for a dispensed statin medication between January 1, 2012, and June 30, 2016, we arrived at the study cohort that included a total of 89,267 patients (see Appendix A for an attrition diagram, available in online article), of which 15,313 (17.2\%) were secondary prevention patients. These eligible patients all had LDL-C levels measured between 6 and 18 months after their index dates. A total of $66.3 \%$ of patients in the cohort at large were below the LDL-C threshold of $100 \mathrm{mg}$ per $\mathrm{dL}$, the remainder $(33.7 \%)$ were equal to or above. Table 1 provides a 
TABLE 2 LDL-C Levels, FRSCVD, Potential LDL-C Reduction, and Potential Relative and Absolute Reduction in 10-Year Risk for Those with LDL-C $\geq 100 \mathrm{mg}$ per $\mathrm{dL}$ in the Study Cohort at Large

\begin{tabular}{|c|c|c|c|}
\hline Outcomes & $\begin{array}{c}\text { Patients with } \\
\text { LDL-C }<100 \mathrm{mg} \text { per dL }\end{array}$ & $\begin{array}{c}\text { Patients with } \\
\text { LDL-C } \geq 100 \mathrm{mg} \text { per dL }\end{array}$ & $P$ Value \\
\hline Number & 59,184 & 30,083 & - \\
\hline LDL-C, mg per dL, mean (SD) & $71.9 \quad(17.5)$ & $128.7 \quad(27.7)$ & $<0.001$ \\
\hline \multicolumn{4}{|l|}{ FRSCVDa $^{a}$} \\
\hline Mean (SD) & $0.2226(0.1633)$ & $0.2278(0.1724)$ & 0.097 \\
\hline Missing & 50,023 & 25,929 & - \\
\hline Potential LDL-C reduction, mg per dL, mean (SD) & - & $28.7 \quad(27.7)$ & - \\
\hline Potential reduction in relative risk of CVD, \% & - & 14.8 & - \\
\hline Potential absolute reduction in 10 -year CVD risk, \% & - & 3.9 & - \\
\hline
\end{tabular}

general description of the cohort with regard to demographics, clinical and laboratory characteristics, and concomitant health conditions.

With a mean age of about 66.3 years, our study population was elderly. Patients below the LDL-C threshold of $100 \mathrm{mg}$ per dL were approximately 4 years older than those at or above. The majority of patients in the below-threshold group were between 65 and 74 years. As patients aged, an increasing proportion of patients were in the below-threshold group within each age group. A disproportionate number of women were in the at-or-above-threshold group. Within racial groups, the lowest proportion in the at-or-above-threshold group was among whites (32.8\%), while the highest was among blacks (44.1\%).

Most patients (19,332 or $64.3 \%)$ at or above their LDL-C threshold were within $30 \mathrm{mg}$ per $\mathrm{dL}$ of it, making it likely that they could be brought to the threshold using adjunctive therapy (Appendix B, available in online article). As expected, triglycerides were substantially higher in the at-or-abovethreshold group than in the below-threshold group. Systolic blood pressure was slightly elevated but fairly similar between the 2 groups, although this finding should be viewed with caution since it is based on a fairly small subsample. Consistent with that observation, antihypertensive treatment rose for both groups after the index date. More patients below than at-or-above threshold were on antihypertensive treatment both before and after the index date. For patients for whom smoking status could be approximated from clinical records, either before or after the index date, smoking rates were between 32\% and 34\%. Smoking status did not appear to be associated with meeting or failing to meet the LDL-C threshold. Aspirin use for the prevention of CVD, which was at $32.1 \%$ and $24.1 \%$ for the below-threshold and at-or-above-threshold groups before the index date, rose to $45.8 \%$ and $37.5 \%$ after it, respectively.

Adherence to the statin therapy regimen, as judged by a medication possession ratio of $80 \%$ or greater, was $57.4 \%$ in the cohort. It was higher in the below-threshold group (66.1\%) than in the at-or-above-threshold group (40.3\%). Of the patients who adhered to therapy, $23.7 \%$ had LDL-C levels that did not meet the threshold. In both groups, the overwhelming majority of patients were treated with moderate-intensity statins, followed by high- and low-intensity statins.

Patients below the threshold had a higher proportion of every concomitant health condition compared with patients at or above the threshold. Diabetes was the most common concomitant health condition, including $34.3 \%$ of patients for the below-threshold group and $23.4 \%$ for the at-or-above-threshold group. The proportion of patients with other conditions was in the single digits, with the exception of congestive heart failure (11.4\%) and prior MI (10.3\%) in the below-threshold group.

Missing values were, generally, not an issue with the exception of smoking status and blood pressure where 37\% and 82\% of all patients, respectively, had no values. When all the significant factors (except for smoking and blood pressure, which would have greatly reduced the sample size) were entered into a multivariable model, adherence and use of high-intensity statins remained strong predictors of threshold attainment after controlling for all other factors. All baseline characteristics and treatments were still factors except for prior use of antihypertensives.

Table 2 shows CVD risk in the cohort at large. In the below-threshold group, LDL-C values had a mean of 71.9 mg per $\mathrm{dL}$, while in the at-or-above-threshold group, the mean was $128.7 \mathrm{mg}$ per $\mathrm{dL}$. In the below-threshold group, the mean risk score $(0.2226)$ was slightly lower than in the at-or-above-threshold group (0.2278). Reducing LDL-C to $<100$ mg per dL in the 30,083 patients at-or-above-threshold could possibly reduce absolute CVD risk by $3.9 \%$, from $22.78 \%$ to $18.88 \%$, avoiding 1,173 CVD events over 10 years. This potential $14.8 \%$ relative risk reduction translates to a theoretical saving of $\$ 1,455(=\$ 37,300 \times 0.039)$ per patient in the at-or-above threshold group if their LDL-C could be treated to threshold Unfortunately, a large proportion of patients (85\%) did not 


\begin{tabular}{|c|c|c|c|}
\hline \multirow{3}{*}{$\begin{array}{l}\text { TABLE } 3 \\
\\
\text { Demographics } \\
\text { Total } \\
\end{array}$} & \multicolumn{3}{|c|}{$\begin{array}{l}\text { jeneral Description of Patient Cohort } \\
\text { reated with Statins for Secondary } \\
\text { revention with and Without Dyslipidemia }\end{array}$} \\
\hline & $\begin{array}{l}\text { Number }(\%) \text { of } \\
\text { Patients with } \\
\text { LDL }<70 \mathrm{mg} \\
\text { per dL }\end{array}$ & $\begin{array}{l}\text { Number (\%) of } \\
\text { Patients with } \\
\text { LDL } \geq 70 \mathrm{mg} \\
\text { per dL }\end{array}$ & \multirow{2}{*}{$\frac{P \text { Value }^{\mathrm{b}}}{-}$} \\
\hline & $6,409 \quad(41.9)$ & $8,904 \quad(58.1)$ & \\
\hline \multicolumn{4}{|l|}{ Age } \\
\hline Mean (SD) & $70.58 \quad(10.4)$ & $68.23(10.8)$ & $<0.001$ \\
\hline $45-54$ & $492 \quad(7.7)$ & $1,111 \quad(12.5)$ & \multirow{4}{*}{$<0.001$} \\
\hline $55-64$ & $1,208 \quad(18.9)$ & $1,995 \quad(22.4)$ & \\
\hline $65-74$ & $2,320(36.2)$ & $3,091 \quad(34.7)$ & \\
\hline$\geq 75$ & $2,389 \quad(37.3)$ & $2,707 \quad(30.4)$ & \\
\hline \multicolumn{4}{|l|}{ Gender } \\
\hline Female & $2,386 \quad(37.2)$ & $4,245 \quad(47.7)$ & \multirow{2}{*}{$<0.001$} \\
\hline Male & $4,023 \quad(62.8)$ & $4,659(52.3)$ & \\
\hline \multicolumn{4}{|l|}{ Ethnicity } \\
\hline Black & $423 \quad(6.6)$ & $852 \quad(9.6)$ & \multirow{3}{*}{$<0.001$} \\
\hline Other & $268 \quad(4.2)$ & $324 \quad(3.7)$ & \\
\hline White & $5,708 \quad(89.2)$ & $7,706(86.8)$ & \\
\hline Missing & 10 & 22 & - \\
\hline \multicolumn{4}{|c|}{ Clinical and laboratory characteristics } \\
\hline \multicolumn{4}{|l|}{ Triglyceride } \\
\hline Mean (SD) & $122.46(23.0)$ & $174.25(36.8)$ & $<0.001$ \\
\hline Missing & 243 & 495 & - \\
\hline \multicolumn{4}{|l|}{ Systolic blood pressure } \\
\hline Mean (SD) & $128.78 \quad(19.1)$ & $131.17 \quad(19.4)$ & $<0.001$ \\
\hline Missing & 4,535 & 6,336 & - \\
\hline \multicolumn{4}{|l|}{ Smokingc } \\
\hline & $1,914 \quad(33.7)$ & $2,915 \quad(37.1)$ & $<0.001$ \\
\hline Missing & 243 & 495 & - \\
\hline \multicolumn{4}{|l|}{ Aspirin } \\
\hline Befored & $3,983 \quad(62.2)$ & $5,278 \quad(59.3)$ & $<0.001$ \\
\hline Afterd & $4,640 \quad(74.2)$ & $6,293(70.7)$ & 0.020 \\
\hline \multicolumn{4}{|c|}{ Antihypertensive treatment } \\
\hline Befored $^{\mathrm{d}}$ & $3,756(58.6)$ & $5,106 \quad(57.4)$ & 0.119 \\
\hline Afterd & $4,741 \quad(74.0)$ & $6,370(71.5)$ & 0.001 \\
\hline \multicolumn{4}{|c|}{ Compliance with statin regimen (MPR $\geq 80 \%$ ) } \\
\hline & $4,292 \quad(67.0)$ & $4,381 \quad(49.2)$ & $<0.001$ \\
\hline Missing & $\begin{array}{c}1 \\
\text { (before index date) }\end{array}$ & $\begin{array}{c}4 \\
\text { (after index date) }\end{array}$ & - \\
\hline \multicolumn{4}{|c|}{ Intensity of initial statin regimen } \\
\hline High & $2,026 \quad(31.6)$ & $2,283(25.6)$ & \\
\hline Moderate & $4,013 \quad(62.6)$ & $5,899(66.3)$ & $<0.001$ \\
\hline Low & $370 \quad(5.8)$ & $722 \quad(8.1)$ & \\
\hline \multicolumn{4}{|l|}{ Health conditions } \\
\hline Diabetes-after ${ }^{\mathrm{d}}$ & $4,127 \quad(64.4)$ & $5,130 \quad(57.6)$ & $<0.001$ \\
\hline Congestive heart failure & $2,396 \quad(37.4)$ & $2,778 \quad(31.2)$ & $<0.001$ \\
\hline $\mathrm{PAD}$ & $1,603(25.0)$ & $2,354 \quad(26.4)$ & 0.047 \\
\hline Stroke & $1,538(24.0)$ & $2,241 \quad(25.2)$ & 0.097 \\
\hline Prior MI & $2,698 \quad(42.1)$ & $3,450(38.8)$ & $<0.001$ \\
\hline \multicolumn{4}{|c|}{$\begin{array}{l}\text { Note: All values in this table are } n(\%) \text { unless indicated otherwise. } \\
{ }^{a} \text { Defined as } L D L-C \geq 70 \mathrm{mg} \text { per } \mathrm{dL} \text {. } \\
{ }^{b} P \text { values denote the statistical significance of differences for values within rows. } \\
\text { 'Smoking was mentioned in clinical notes before and up to the index date. } \\
{ }^{d} \text { Missing days-of-supply data. } \\
\text { LDL-C=low-density lipoprotein cholesterol; } M I=\text { myocardial infarction; } M P R=\text { medi- } \\
\text { cation possession ratio; } P A D=\text { peripheral artery disease; } S D=\text { standard deviation. }\end{array}$} \\
\hline
\end{tabular}

have sufficient data to calculate the FRSCVD, suggesting that these results should be further validated.

\section{Descriptive Analyses for the Secondary Prevention Cohort}

The subgroup of patients treated with statins for secondary prevention included 15,313 patients. Of those, $41.8 \%$ were below the LDL-C threshold of $70 \mathrm{mg}$ per $\mathrm{dL}$, the remainder (58.1\%) were at or above the threshold (errors due to rounding). Table 3 provides a general description of cohort demographics, clinical characteristics, and concomitant health conditions. $P$ values are provided to indicate the statistical significance of differences for values within rows. We describe this group separately without reference to the cohort at large, since the overall cohort included it.

The mean age of this subcohort was 69.2 years. Patients below the LDL-C threshold of $70 \mathrm{mg}$ per $\mathrm{dL}$ were approximately 2 years older than those at-or-above. The majority of individuals in the secondary prevention cohort were aged 65 years or more. The proportion of patients below threshold generally increased with age, from 31\% in the $45-54$ age group to $47 \%$ in the $\geq 75$ age group. A significantly higher proportion (64.0\%) of women than men (53.7\%) had LDL-C at or above the threshold. The percentage of patients of black ethnicity in the at-or-above-threshold group was twice $(66.8 \%)$ that in the below-threshold group (33.2\%). For whites, that ratio was only 1.35 (57.5\% vs. $42.3 \%)$.

With regard to clinical and laboratory characteristics, most patients $(5,565$ or $62.5 \%)$ at or above threshold were within $30 \mathrm{mg}$ per dL of it (data not shown). Triglycerides were substantially higher in the at-or-above-threshold group than in the below-threshold group. Systolic blood pressure was slightly elevated and fairly similar between the 2 groups. For patients for whom smoking status could be approximated from clinical records, smoking rates were $33.7 \%$ in the below-threshold group and $37.1 \%$ in the other. Aspirin use for the prevention of CVD, which was at $62.2 \%$ and $59.3 \%$ before the index date for the below-threshold and at-or-above-threshold groups, respectively, rose by approximately $16 \%$ and 19\%, respectively, in the 2 groups after the index date. Antihypertensive treatment also rose post-index date in both groups.

Adherence to the statin therapy regimen was $56.7 \%$ for the cohort. It was higher in the below-threshold group (67.0\%) than in the at-or-above-threshold group (49.2\%). Of the patients who adhered to therapy, 50.5\% had LDL-C levels that did not meet the threshold. With regard to the intensity of statins, compared with the at-or-above-threshold group, the below-threshold group had initiated therapy more often with high-intensity statins (31.6\% compared with 25.6\%).

A higher proportion of below-threshold patients had diabetes, congestive heart failure, and prior MI compared with the above-threshold patients (see Table 3). 
TABLE 4 LDL-C Levels, FRSCVD, Potential LDL-C Reduction, and Potential Relative and Absolute Reduction in 10-Year Risk for Those with LDL-C $\geq 70 \mathrm{mg}$ per $\mathrm{dL}$ in the Secondary Prevention Cohort

\begin{tabular}{|c|c|c|c|}
\hline Outcomes & $\begin{array}{c}\text { Patients with } \\
\text { LDL-C } \geq 70 \mathrm{mg} \text { per dL }\end{array}$ & $\begin{array}{c}\text { Patients with } \\
\text { LDL-C }<70 \mathrm{mg} \text { per } \mathrm{dL}\end{array}$ & $P$ Value \\
\hline Number & 6,409 & 8,904 & - \\
\hline LDL-C, mg per dL, mean (SD) & $53.0 \quad(12.3)$ & $100.4 \quad(29.2)$ & $<0.001$ \\
\hline \multicolumn{4}{|l|}{ FRSCVD $^{a}$} \\
\hline Mean (SD) & $0.2607(0.1718)$ & $0.2956(0.1819)$ & $<0.001$ \\
\hline Missing & 4,718 & 6,699 & - \\
\hline Potential LDL-C reduction, mg per dL, mean (SD) & - & $30.4 \quad(29.2)$ & - \\
\hline Potential relative risk reduction per CTT, \% & - & 15.7 & - \\
\hline Potential absolute reduction in 10-year CVD risk, \% & - & 5.1 & - \\
\hline
\end{tabular}

Missing values were, generally, not an issue with the exception of smoking status and systolic blood pressure where $11.6 \%$ and $71.0 \%$ of all patients, respectively, had no values. Controlling for all covariates in a multivariable model, adherence remained siginificantly associated with reaching LDL-C threshold. However, high- and moderate-intensity statin was only marginally associated with reaching the threshold compared with low-intensity statin $(P<0.05$ with a one-sided test). Baseline characteristics that remained factors included race and gender.

Table 4 shows the CVD risks for the secondary prevention cohort. In the below-threshold group, mean LDL-C was $53.0 \mathrm{mg}$ per $\mathrm{dL}$, while in the at-or-above-threshold group, the mean was $100.4 \mathrm{mg}$ per $\mathrm{dL}$. The mean post-index date risk of CVD events was 0.2607 in the below-threshold group, lower than in the at-or-above-threshold group (0.2956) by an absolute difference of $3.5 \%$ that was statistically significant.

Reducing LDL-C to $<70 \mathrm{mg}$ per $\mathrm{dL}$ in the 8,904 patients at or above the threshold could possibly reduce absolute CVD risk by $5.1 \%$, from $29.56 \%$ to $24.46 \%$, avoiding 454 CVD events over 10 years, and translating to cost savings of about $\$ 1,902$ per patient at or above threshold in this subgroup. Again, a large proportion of missing FRSCVD values suggests that these results need further validation.

\section{Discussion}

Reducing LDL-C to reasonable levels remains an important strategy for lowering morbidity and mortality in CVD. ${ }^{47,48}$ This study estimated the frequency of not attaining reasonable LDL-C thresholds among patients initiating statin therapy in a network of independent health care systems representing diverse patients and providers in Indiana. It calculated the potential for reducing CVD risk if patients achieved the threshold, as well as resulting in potential cost savings for treating CVD events.

We chose to use thresholds for LDL-C because our study period included data from before and after the 2013 ACC/AHA guidelines were published. ${ }^{16,17,48}$ We do not know how quickly our clinicians adopted the new guidelines, and multiple outcomes trials of high-risk patients on statin therapy with LDL-C levels that remained elevated have shown the benefits of lowering LDL-C levels to reduce CVD risk..$^{40-42}$ The 2018 guidelines confirmed our thresholds for the high-risk group. ${ }^{17}$

In our cohort at large, $66.3 \%$ of all patients achieved the threshold LDL-C level of $<100 \mathrm{mg}$ per $\mathrm{dL}$, mirroring the results of another community-based EHR data analysis of 250,700 patients almost exactly and at the high end of results published previously. ${ }^{8-14}$ Threshold achievement in the secondary prevention cohort $(41.8 \%)$ was somewhat higher than in similar populations $(18.7 \%, 26.0 \%$, and $37 \%)$, likely because of variation in study populations., ${ }^{910,49}$ Although we included only patients who were at least aged 45 years, the majority of patients were aged 65 years or more in both cohorts, consistent with other studies. ${ }^{4,50,51}$ Patient characteristics that were independently associated with reaching threshold included age, gender, and race as well as all prior chronic cardiovascular conditions. The lower percentage of women reaching the threshold appears to deviate from previous findings.

Adherence is an important consideration in statin therapy, especially in helping patients reach therapeutic thresholds. ${ }^{52-56}$ Increased adherence was associated with higher probability of reaching the threshold, even after accounting for patient characteristics that differed between groups. However, a fairly large percentage of patients who adhered to therapy had LDL-C levels that did not reach the threshold $(23.7 \%$ in the general and $50.5 \%$ in the secondary prevention cohorts). Multiple reasons could be responsible for this finding, such as limitations in the MPR as a valid measure of patient adherence, and a mismatch between the therapeutic needs of a patient and the type and dosage of statin prescribed.

The hypothetical relative risk reduction of $14.8 \%$ and $15.7 \%$ in the 2 cohorts is roughly similar to that seen in recent $\mathrm{CV}$ outcomes trials, making the achievement of actual clinical 
benefits likely. ${ }^{40,41}$ Corresponding expected cost savings for avoided CVD events are $\$ 1,455$ and $\$ 1,902$ per treated patient over 10 years. While several economic analyses for therapies to lower known risk factors for CVD exist, none was directly comparable. ${ }^{35-38}$

We estimated costs for treating potentially avoidable CV events conservatively. CVD treatment costs in patients with hypertension and diabetes are higher than in patients without, leading us to likely underestimate potential cost savings. ${ }^{30,57-62}$ In addition, we did not consider ongoing treatment costs for CVD events beyond the first year. Finally, the FRS was designed for primary, not secondary, prevention, and thus may underestimate risk for secondary prevention patients. Despite this conservative approach, aggregated to large patient populations, these figures could translate into significant cost savings.

\section{Limitations}

Generalizability of our findings may be limited because of our focus on the population of Indiana. Since we only included individuals in our study who sought care and filled a statin prescription, we cannot quantify the unmet treatment need in individuals with or at risk of CVD who did not meet these criteria.

Our study also does not include patients who were prescribed a statin and did not fill the prescription. Primary nonadherence rates of between 13\% and 34.1\% have been reported, and $15.4 \%$ of patients did not fill a new statin order within 90 days of the prescription. ${ }^{63}$ These patients tended to be younger and healthier than adherent patients, and are thus likely underrepresented in our study.

We also do not know whether clinicians in our study targeted a particular LDL-C level or used current guidelines or clinical protocols, such as titration or other interventions, to optimize statin therapy. ${ }^{13,64}$ However, regardless of guidelines followed, CTT evidence suggests that reducing LDL-C levels as described in our study reduces the risk of CVD events. Last, data extracted from EHRs lack the standardization and rigor of research data collected in dedicated trials, and thus can influence results in a variety of ways.

Finally, the absolute risk, potential risk reduction, and forecast costs avoided-while based on published algorithms and studies-are by their nature speculative. They are used here to illustrate, not define, the effect on a population of patients with high LDL-C levels.

\section{Conclusions}

This study has shown a large and potentially important gap between reasonable LDL-C thresholds and actual LDL-C levels achieved by contemporary statin regimens within a large, diversified patient population in Indiana. Achieving these thresholds could translate into substantial CV risk reduction and cost savings.

\section{Authors}

TITUS SCHLEYER, DMD, PhD, Regenstrief Institute, and Indiana University School of Medicine, Indianapolis. SIU HUI, PhD; JANE WANG, PhD; ZUOYI ZHANG, PhD; KRISTINA KNAPP, BA; and JAROD BAKER, MS, Regenstrief Institute, Indianapolis, Indiana. MONICA CHASE, PhD, and ROBERT BOGGS, PhD, Merck, Kenilworth, New Jersey. ROSS J. SIMPSON, JR, MD, PhD, Division of Cardiology, University of North Carolina at Chapel Hill.

AUTHOR CORRESPONDENCE: Titus Schleyer, DMD, PhD, Regenstrief Institute, 1101 W. 10th St., Indianapolis, IN 462024800. Tel.: 317.274.9204; E-mail: schleyer@regenstrief.org.

\section{DISCLOSURES}

Funding support for this study was provided by Merck (Kenilworth, NJ) Chase and Boggs are employed by Merck. Simpson is a consultant to Merck and Pfizer. The other authors have nothing to disclose.

\section{ACKNOWLEDGMENTS}

Schleyer gratefully acknowledges support from the Clem MacDonald chair account and the Lilly Endowment Physician Scientist Initiative.

\section{REFERENCES}

1. Mitchell AP, Simpson RJ. Statin cost effectiveness in primary prevention: a systematic review of the recent cost-effectiveness literature in the United States. BMC Res Notes. 2012;5:373. Available at: https://bmcresnotes.biomedcentral. com/track/pdf/10.1186/1756-0500-5-373. Accessed February 28, 2019.

2. Ward S, Lloyd Jones M, Pandor A, et al. A systematic review and economic evaluation of statins for the prevention of coronary events. Health Technol Assess. 2007;11(14):1-160, iii-iv. Available at: http://www.journalslibrary.nihr. ac.uk/hta/volume-11/issue-14. Accessed February 28, 2019.

3. Kamboj L, Oh P, Levine M, et al. Cost effectiveness of a systematic guidelines-based approach to the prevention and management of vascular disease in a primary care setting. Int J Cardiol. 2016;203:893-99.

4. Pandya A, Sy S, Cho S, Weinstein MC, Gaziano TA. Cost-effectiveness of 10-year risk thresholds for initiation of statin therapy for primary prevention of cardiovascular disease. JAMA. 2015;314(2):142-50. Available at: http:// jama.jamanetwork.com/article.aspx?doi=10.1001/jama.2015.6822. Accessed February 28, 2019.

5. The importance of pharmacovigilance - safety monitoring of medicinal products. World Health Organ. 2002;3:9-14. Available at: http://apps.who.int/ medicinedocs/pdf/s4893e/s4893e.pdf. Accessed February 28, 2019.

6. Cohen JD, Brinton EA, Ito MK, Jacobson TA. Understanding Statin Use in America and Gaps in Patient Education (USAGE): an internet-based survey of 10,138 current and former statin users. J Clin Lipidol. 2012;6(3):208-15.

7. Writing Committee, Lloyd-Jones DM, Morris PB, et al. 2016 ACC expert consensus decision pathway on the role of non-statin therapies for LDLcholesterol lowering in the management of atherosclerotic cardiovascular disease risk: a report of the American College of Cardiology Task Force on clinical expert consensus documents. J Am Coll Cardiol. 2016;68(1):92-125. Available at: https://www.sciencedirect.com/science/article/pii/ S0735109716323981?via\%3Dihub. Accessed February 28, 2019.

8. Wong ND, Chuang J, Zhao Y, Rosenblit PD. Residual dyslipidemia according to low-density lipoprotein cholesterol, non-high-density lipoprotein cholesterol, and apolipoprotein B among statin-treated U.S. adults: National Health and Nutrition Examination Survey 2009-2010. J Clin Lipidol. 2015;9(4):525-32 
9. Karalis DG, Victor B, Ahedor L, Liu L. Use of lipid-lowering medications and the likelihood of achieving optimal LDL-cholesterol goals in coronary artery disease patients. Cholesterol. 2012;2012:861924.

10. Jones PH, Nair R, Thakker KM. Prevalence of dyslipidemia and lipid goal attainment in statin-treated subjects from 3 data sources: a retrospective analysis. J Am Heart Assoc. 2012;1(6):e001800.

11. U.S. Department of Health and Human Services, Food and Drug Administration. Guidance for industry: good pharmacovigilance practices and pharmacoepidemiologic assessment. March 22, 2005. Available at: https://permanent.access.gpo.gov/LPS116059/04d-0189-gdl0002.pdf. Accessed February 28, 2019.

12. Wei MY, Ito MK, Cohen JD, Brinton EA, Jacobson TA. Predictors of statin adherence, switching, and discontinuation in the USAGE survey: Understanding the Use of Statins in America and Gaps in patient education. J Clin Lipidol. 2013;7(5):472-83.

13. Foley KA, Simpson RJ Jr, Crouse JR 3rd, Weiss TW, Markson LE, Alexander CM. Effectiveness of statin titration on low-density lipoprotein cholesterol goal attainment in patients at high risk of atherogenic events. Am J Cardiol. 2003;92(1):79-81.

14. Nag SS, Daniel GW, Bullano MF, et al. LDL-C goal attainment among patients newly diagnosed with coronary heart disease or diabetes in a commercial HMO. J Manag Care Pharm. 2007;13(8):652-63. Available at: https:// www.jmcp.org/doi/10.18553/jmcp. 2007.13.8.652.

15. Gitt AK, Lautsch D, Ferrieres J, et al. Low-density lipoprotein cholesterol in a global cohort of 57,885 statin-treated patients. Atherosclerosis. 2016;255:200-09.

16. Stone NJ, Robinson JG, Lichtenstein AH, et al. 2013 ACC/AHA guideline on the treatment of blood cholesterol to reduce atherosclerotic cardiovascular risk in adults: a report of the American College of Cardiology/ American Heart Association Task Force on Practice Guidelines. Circulation. 2014;129(25 Suppl 2):S1-45.

17. Grundy SM, Stone NJ, Bailey AL, et al. 2018 AHA/ACC/AACVPR/ AAPA/ABC/ACPM/ADA/AGS/APhA/ASPC/NLA/PCNA Guideline on the Management of Blood Cholesterol. Circulation. November 10, 2018 [Epub ahead of print]. Available at: https://www.ncbi.nlm.nih.gov/ pubmed/30586774. Accessed March 23, 2019.

18. Ballantyne CM, Raichlen JS, Cain VA. Statin therapy alters the relationship between apolipoprotein B and low-density lipoprotein cholesterol and non-high-density lipoprotein cholesterol targets in high-risk patients: the MERCURY II (Measuring Effective Reductions in Cholesterol Using Rosuvastatin) trial. J Am Coll Cardiol. 2008;52(8):626-32. Available at: https://www.sciencedirect.com/science/article/pii/ S073510970801930X?via\%3Dihub. Accessed February 28, 2019.

19. Sirimarco G, Labreuche J, Bruckert E, et al. Atherogenic dyslipidemia and residual cardiovascular risk in statin-treated patients. Stroke. 2014 May;45(5):1429-36. Available at: https://www.ahajournals.org/doi/ pdf/10.1161/STROKEAHA.113.004229. Accessed February 28, 2019.

20. Pencina MJ, Navar-Boggan AM, D’Agostino RB, et al. Application of new cholesterol guidelines to a population-based sample. N Engl J Med. 2014;370(15):1422-31. Available at: https://www.cdc.gov/nchs/data/series/ sr_02/sr02_161.pdf. Accessed February 28, 2019.

21. Shepherd J. Who should receive a statin these days? Lessons from recent clinical trials. J Intern Med. 2006;260(4):305-19.

22. LaRosa JC, Grundy SM, Waters DD, et al. Intensive lipid lowering with atorvastatin in patients with stable coronary disease. $N$ Engl J Med. 2005;352(14):1425-35. Available at: https://pure.uva.nl/ws/ files/3935025/45349_205993y.pdf. Accessed February 28, 2019.

23. McDonald CJ, Overhage JM, Barnes M, et al. The Indiana network for patient care: a working local health information infrastructure. Health Aff (Millwood). 2005;24(5):1214-20.

24. Overhage JM. The Indiana Health Information Exchange. In: Health Information Exchange: Navigating and Managing a Network of Health Information Systems. Waltham, MA: Academic Press; 2016:267-79.
25. Institute of Medicine; Committee of Improving the Patient Record, Dick RS, Steen EB, Detmer DE, eds. The Computer-Based Patient Record: An Essential Technology for Health Care. Washington, DC: National Academy Press; 1991.

26. Bourgeois FC, Olson KL, Mandl KD. Patients treated at multiple acute health care facilities. Arch Intern Med. 2010;170(22):1989-95. Available at: https://jamanetwork.com/journals/jamainternalmedicine/fullarticle/776461. Accessed February 28, 2019.

27. Wei WQ, Leibson CL, Ransom JE, et al. Impact of data fragmentation across healthcare centers on the accuracy of a high-throughput clinical phenotyping algorithm for specifying subjects with type 2 diabetes mellitus. J Am Med Inform Assoc. 2012;19(2):219-24.

28. Porter ME. What is value in health care? N Engl J Med. 2010;363(26): $2477-81$

29. O'Sullivan AK, Rubin J, Nyambose J, Kuznik A, Cohen DJ, Thompson D. Cost estimation of cardiovascular disease events in the U.S. Pharmacoeconomics. 2011;29(8):693-704.

30. Chapman RH, Liu LZ, Girase PG, Straka RJ. Determining initial and follow-up costs of cardiovascular events in a U.S. managed care population. BMC Cardiovasc Disord. 2011;11:11. Available at: https://bmccardiovascdisord.biomedcentral.com/track/pdf/10.1186/1471-2261-11-11. Accessed February 28, 2019.

31. Bonafede M, Johnson B, Paoli C, Gandra S. Annual fatal and nonfatal cardiovascular event costs among non-elderly commercially insured adults with hyperlipidemia in the United States. Value Health. 2016;19(3):A46. Available at: http://linkinghub.elsevier.com/retrieve/pii/ S1098301516001728. Accessed February 28, 2019.

32. Lazar LD, Pletcher MJ, Coxson PG, Bibbins-Domingo K, Goldman L. Cost-effectiveness of statin therapy for primary prevention in a low-cost statin era. Circulation. 2011;124(2):146-53.

33. Erickson KF, Japa S, Owens DK, Chertow GM, Garber AM, GoldhaberFiebert JD. Cost-effectiveness of statins for primary cardiovascular prevention in chronic kidney disease. J Am Coll Cardiol. 2013;61(12):1250-58. Available at: https://www.sciencedirect.com/science/article/pii/ S0735109713002623?via\%3Dihub. Accessed February 28, 2019.

34. Burgers LT, Nauta ST, Deckers JW, Severens JL, Redekop WK. Is it cost-effective to use a test to decide which individuals with an intermediate cardiovascular disease risk would benefit from statin treatment? Int J Cardiol. 2014;176(3):980-87.

35. Grabner M, Winegar DA, Punekar RS, Quimbo RA, Cziraky MJ, Cromwell WC. Cost effectiveness of achieving targets of low-density lipoprotein particle number versus low-density lipoprotein cholesterol level. Am J Cardiol. 2017;119(3):404-09. Available at: https://linkinghub.elsevier.com/ retrieve/pii/S0002914916317398. Accessed February 28, 2019.

36. Rizzo JA, Mallow PJ, Waters HC, Pokrywka GS. Managing to low-density lipoprotein particles compared with low-density lipoprotein cholesterol: a cost-effectiveness analysis. J Clin Lipidol. 2013;7(6):642-52.

37. Folse HJ, Goswami D, Rengarajan B, Budoff M, Kahn R. Clinical- and cost-effectiveness of LDL particle-guided statin therapy: A simulation study. Atherosclerosis. 2014;236(1):154-61. Available at: https://linkinghub.elsevier. com/retrieve/pii/S002191501401257X. Accessed February 28, 2019.

38. Gandra SR, Villa G, Fonarow GC, et al. Cost-effectiveness of LDL-C lowering with evolocumab in patients with high cardiovascular risk in the United States. Clin Cardiol. 2016;39(6):313-20. Available at: https://onlinelibrary.wiley.com/doi/pdf/10.1002/clc.22535. Accessed February 28, 2019.

39. Grundy SM, Cleeman JI, Bairey Merz CN, et al. Implications of recent clinical trials for the National Cholesterol Education Program Adult Treatment Panel III guidelines. Circulation. 2004;110(2):227-39.

40. Sabatine MS, Giugliano RP, Keech AC, et al. Evolocumab and clinical outcomes in patients with cardiovascular disease. N Engl J Med. 2017;376(18):1713-22. Available at: http://spiral.imperial.ac.uk/bitstream/10044/1/48891/7/nejmoal615664.pdf. Accessed February 28, 2019. 
41. HPS3/TIMI55-REVEAL Collaborative Group, Bowman L, Hopewell JC, et al. Effects of anacetrapib in patients with atherosclerotic vascular disease N Engl J Med. 2017;377(13):1217-27.

42. Cannon CP, Blazing MA, Giugliano RP, et al. Ezetimibe added to statin therapy after acute coronary syndromes. N Engl J Med. 2015;372(25):2387-97. Available at: https://www.nejm.org/doi/pdf/10.1056/NEJMoal410489.

Accessed February 28, 2019

43. Jacobson TA, Ito MK, Maki KC, et al. National Lipid Association recommendations for patient-centered management of dyslipidemia: part 1-full report. J Clin Lipidol. 2015;9(2):129-69.

44. Menzin J, Aggarwal J, Boatman B, et al. Ezetimibe use and LDL-C goal achievement: a retrospective database analysis of patients with clinical atherosclerotic cardiovascular disease or probable heterozygous familial hypercholesterolemia. J Manag Care Spec Pharm. 2017;23(12):1270-76. Available at: https://www.jmcp.org/doi/10.18553/jmcp.2017.16414.

45. REVEAL Collaborative Group, Bowman L, Chen F, et al. Randomized Evaluation of the Effects of Anacetrapib through Lipid-modification

(REVEAL)-A large-scale, randomized, placebo-controlled trial of the clinical effects of anacetrapib among people with established vascular disease: Trial design, recruitment, and baseline characteristics. Am Heart J. 2017;187:182-90. Available at: https://www.sciencedirect.com/science/article/pii/ S000287031730056X?via\%3Dihub. Accessed February 28, 2019.

46. DeFilippis AP, Young R, Carrubba CJ, et al. An analysis of calibration and discrimination among multiple cardiovascular risk scores in a modern multiethnic cohort. Ann Intern Med. 2015;162(4):266-75. Available at: http:// europepmc.org/backend/ptpmcrender.fcgi?accid=PMC4414494\&blobtype=pdf. Accessed February 28, 2019

47. Navarese EP, Robinson JG, Kowalewski M, et al. Association between baseline LDL-C level and total and cardiovascular mortality after LDL-C lowering: a systematic review and meta-analysis. JAMA. 2018;319(15):1566-79. Available at: https://jamanetwork.com/journals/jama/fullarticle/2678614. Accessed February 28, 2019

48. Soran H, Dent R, Durrington P. Evidence-based goals in LDL-C reduction. Clin Res Cardiol. 2017;106(4):237-48. Available at: https://link.springer.com/ content/pdf/10.1007\%2Fs00392-016-1069-7.pdf. Accessed February 28, 2019.

49. Gamboa CM, Safford MM, Levitan EB, et al. Statin underuse and low prevalence of LDL-C control among U.S. adults at high risk of coronary heart disease. Am J Med Sci. 2014;348(2):108-14. Available at: http://europepmc.org/backend/ptpmcrender.fcgi?accid=PMC4108514\&blobtype=pdf. Accessed February 28, 2019.

50. Lo-Ciganic WH, Boudreau RM, Gray SL, et al. Changes in cholesterollowering medications use over a decade in community-dwelling older adults. Ann Pharmacother. 2013;47(7-8):984-92.

51. Gu Q, Paulose-Ram R, Burt VL, Kit BK. Prescription cholesterol-lowering medication use in adults aged 40 and over: United States, 2003-2012. NCHS Data Brief. 2014;(177):1-8. Available at: http://www.cdc.gov/nchs/data/ databriefs/dbl77.pdf. Accessed February 28, 2019.

52. Zhao Y, Zabriski S, Bertram C. Associations between statin adherence level, health care costs, and utilization. J Manag Care Pharm. 2014;20(7):70313. Available at: https://www.jmcp.org/doi/10.18553/jmcp.2014.20.7.703.
53. Lin I, Sung J, Sanchez RJ, et al. Patterns of statin use in a real-world population of patients at high cardiovascular risk. J Manag Care Spec Pharm. 2016;22(6):685-98. Available at: https://www.jmcp.org/doi/10.18553/ jmcp.2016.22.6.685.

54. Spence JD, Dresser GK. Overcoming challenges with statin therapy. J Am Heart Assoc. 2016;5(1):e002497. Available at: http://jaha.ahajournals org/lookup/doi/10.1161/JAHA.115.002497. Accessed February 28, 2019.

55. Lardizabal JA, Deedwania PC. Benefits of statin therapy and compliance in high risk cardiovascular patients. Vasc Health Risk Manag. 2010;6:843-53. Available at: https://www.ncbi.nlm.nih.gov/pmc/articles/PMC2952453/pdf/ vhrm-6-843.pdf. Accessed February 28, 2019.

56. Armstrong EJ, Chen DC, Westin GG, et al. Adherence to guidelinerecommended therapy is associated with decreased major adverse cardiovascular events and major adverse limb events among patients with peripheral arterial disease. J Am Heart Assoc. 2014;3(2):e000697. Available at: https://www.ahajournals.org/doi/pdf/10.1161/JAHA.113.000697. Accessed February 28, 2019.

57. Daviglus ML, Liu K, Pirzada A, et al. Cardiovascular risk profile earlier in life and Medicare costs in the last year of life. Arch Intern Med. 2005;165(9):1028-34. Available at: https://jamanetwork.com/journals/ jamainternalmedicine/fullarticle/1152789. Accessed February 28, 2019

58. Huse DM, Song X, Ozminkowski RJ, et al. Impact of rosuvastatin use on costs and outcomes in patients at high risk for cardiovascular disease in US managed care and Medicare populations: a data analysis. Clin Ther 2006;28(9):1425-42.

59. Daviglus ML, Liu K, Greenland P, et al. Benefit of a favorable cardiovascular risk-factor profile in middle age with respect to Medicare costs. N Engl J Med. 1998;339(16):1122-29. Available at: https://www.nejm.org/doi/ pdf/10.1056/NEJM199810153391606. Accessed February 28, 2019.

60. Levenson JW, Skerrett PJ, Gaziano JM. Reducing the global burden of cardiovascular disease: the role of risk factors. Prev Cardiol. 2002;5(4):188-99. Available at: https://onlinelibrary.wiley.com/doi/pdf/10.1111/j.1520037X.2002.00564.x. Accessed February 28, 2019.

61. Oster G, Thompson D, Edelsberg J, Bird AP, Colditz GA. Lifetime health and economic benefits of weight loss among obese persons. Am J Public Health. 1999;89(10):1536-42. Available at: https://www.ncbi.nlm.nih.gov/ pmc/articles/PMC1508787/. Accessed February 28, 2019.

62. Song X, Huse DM, Williams SA, Borok GM, McDonough K, Ozminkowski RJ. A projection of the impact of lipid-lowering therapy on high-risk employee disability and medical costs. J Occup Environ Med. 2006;48(10):1014-22

63. Cheetham TC, Niu F, Green K, et al. Primary nonadherence to statin medications in a managed care organization. J Manag Care Pharm. 2013;19(5):367-74. Available at: https://www.jmcp.org/doi/10.18553/ jmcp.2013.19.5.367.

64. Lester WT, Grant RW, Barnett GO, Chueh HC. Randomized controlled trial of an informatics-based intervention to increase statin prescription for secondary prevention of coronary disease. J Gen Intern Med. 2006;21(1):22-29. Available at: http://europepmc.org/backend/ptpmcrender.fcgi?accid=PMC148 4624\&blobtype=pdf. Accessed February 28, 2019. 
Quantifying Unmet Need in Statin-Treated Hyperlipidemia Patients and the Potential Benefit of Further LDL-C Reduction Through an EHR-Based Retrospective Cohort Study

APPENDIX A Attrition Diagram for General Study Cohort According to Inclusion Criteria

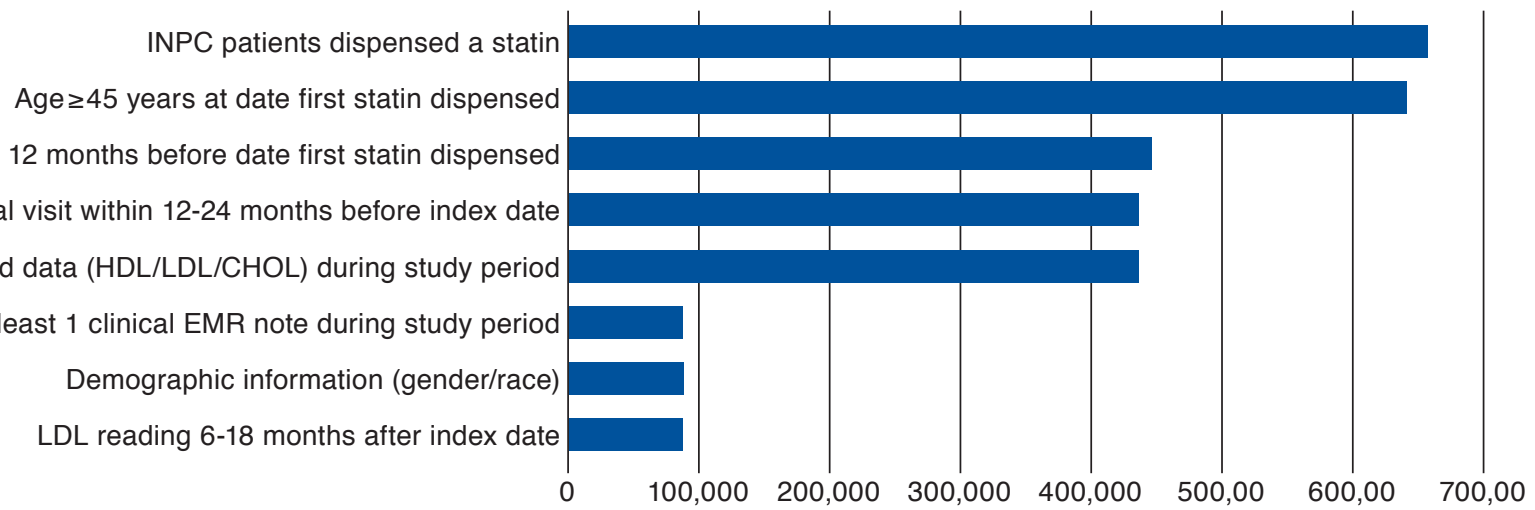

Number of Patients

$\mathrm{CHOL}=$ cholesterol; EMR = electronic medical record; HDL=high-density lipoprotein; INPC = Indiana Network for Patient Care; LDL=low-density lipoprotein

APPENDIX B Distribution of LDL-C Levels in Patients at or Above Threshold of $100 \mathrm{ml}$ per dL in the Cohort at Large

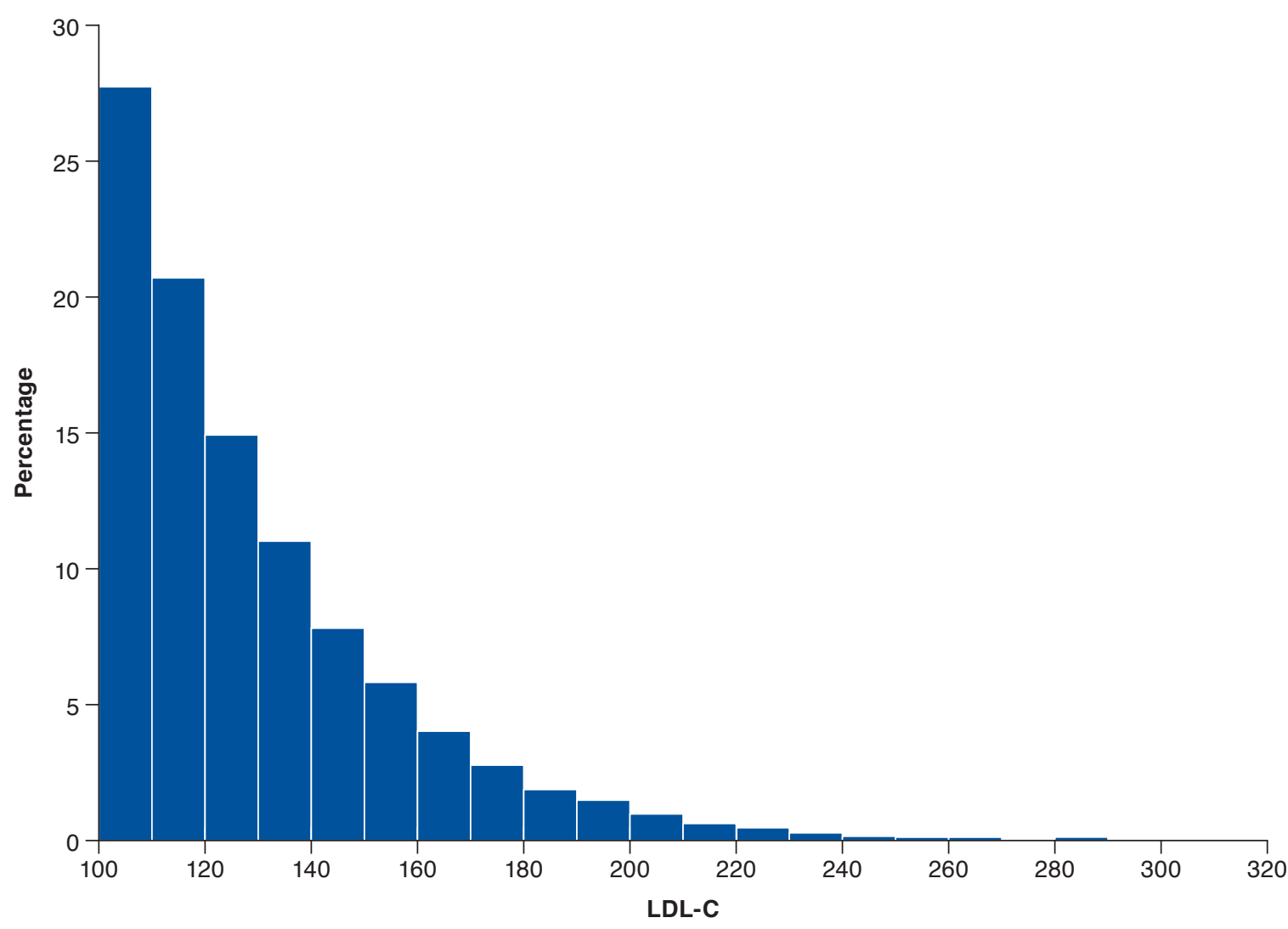

LDL-C =low-density lipoprotein cholesterol. 